\title{
Mentoring in Development of the Regional Education System
}

\author{
Julia Gnezdova \\ Smolensk State University \\ Smolensk, Russia \\ E-mail: Iuliy_67@mail.ru
}

\author{
Ibragim Idilov \\ Grozny State Oil Technical University named after M.D. \\ Millionshikov \\ Grozny, Russia \\ E-mail: dr_idilov_ibrag@mail.ru
}

\begin{abstract}
The paper analyzes the approaches to the organization of mentoring in works of foreign as well as domestic authors on experience of the regional educational institution, shows the mentoring role in the development of personnel structure. Methodical approaches, recommendations on the introduction of mentoring in educational institutions are being considered, in which the order of mentoring organization is defined, and approaches to the choice of mentors and persons are examined. The paper contains the list of actions for implementation of the mentoring and a set of tools promoting the learning efficiency. Today mentoring is an important method of personnel work, providing the fastest adaptation, professional development and career development.
\end{abstract}

Keywords-mentoring; adaptation; career development; education system; region

\section{INTRODUCTION}

Continuity of knowledge, skills and the accumulated experience plays an important role in efficiency of an education system functioning, providing integrity of the organization, efficiency of realization of its functions and observance of the adopted rules of conduct and work of the whole higher school. Taking into account the growing load on the education system, the importance of high-quality and fast adaptation of employees to working conditions and staff increases. The practice of mentoring is not new in use, neither in a Russian, nor in a foreign experience, however with time the technologies of mentoring use have been considerably improved. Depending on the purpose, regional educational institutions use various instruments and types of mentoring. Mentoring is not an influence of fashion and not an innovation, but rather a traditional method of training.
This method is widely applied today. The examples of its use are especially numerous at the industrial enterprises.

The purpose of the publication is the analysis of available scientific literature and results of research of mentoring development in the education system of Russia - the analysis of prerequisites of emergence, formation, evolution and state today. During the research of traditions of mentoring the following methods have been used: analysis of official statistical data, sociological research; method of the analysis of documents. Experience of mentoring in regional higher education institutions of Russia was the focus of authors' attention. Publications and documents and own researches, mentoring in activity at the higher school became an important component of empirical base of research [1].

\section{MODERN MODELS OF MENTORING ORGANIZATION}

Today understanding of the mentoring system application becomes a distinctive feature of any organization [2]. In such organizations a specially organized system of mentoring is applied, or this method is used involuntarily, "by default". Mentoring can be as a form of adaptation of the new employee, and also as a kind of training. In modern conditions mentoring can become an effective form and an important link of training in the organization where the ultimate goal of the tutorial program will consist in "creation" of an effective employee of the organization.

Having deep traditions of mentoring, there is no general definition of this term, and now in administrative sciences as equals are often used the terms "consultation", "coaching", "supervision", "mentoring" [3]. We will compare these models of mentoring presented by foreign authors in "Table I" [4].

TABLE I. COMPARISON OF MODELS OF MENTORING

\begin{tabular}{|c|c|c|c|}
\hline Models & $\begin{array}{c}\text { Descriptions } \\
\end{array}$ & Target groups & Results, effects \\
\hline $\begin{array}{l}\text { Mentorship, } \\
\text { "mentoring" }\end{array}$ & $\begin{array}{l}\text { Transfer to the senior generation and experienced } \\
\text { people the knowledge of performance of tasks }\end{array}$ & All employees & $\begin{array}{l}\text { Training, adaptation. Improvement of communications; } \\
\text { preservation and transfer of knowledge }\end{array}$ \\
\hline "Supervision" & Cooperation of professionals & Middle managers & Progress; definition of needs in training and development. \\
\hline "Shadowing" & $\begin{array}{l}\text { Attachment to the leader for observation of } \\
\text { peculiarities of work }\end{array}$ & $\begin{array}{l}\text { Young specialists; the } \\
\text { candidates interested } \\
\text { in transfer }\end{array}$ & Training, adaptation; retraining; professional motivation \\
\hline
\end{tabular}


Many researchers of mentoring often connect together norms and values in the concept "organizational culture". Often the mentor manages to report effectively the culture of the organization that can be estimated on perception of values and traditions of the company, acquisition of language (informal and technical), characteristic of the organization [5].

Today a technique which most precisely and in many ways can estimate the efficiency of mentoring is Donald Kirkpatrick's model. She gives a chance to take measurements on four levels, using specific tools (tests, questionnaires, observation) for each of them. Such approach allows estimating both quantitative changes, and qualitative that is very important for assessment of mentoring efficiency
[6]. In her model Donald Kirkpatrick has suggested to estimate training in following levels in "Table II":

- Level I - Assessment of reaction of the participant, that is assessment of emotional satisfaction (Reaction);

- Level II - Assessment of the gained knowledge or assessment of changes of knowledge level (Learning);

- Level III - Assessment of behavior change (Behavior);

- Level IV - Assessment of business results for the company (Results).

TABLE II. APPROACH TO ASSESSMENT OF MENTORING BY D. KIRPATRICK

\begin{tabular}{|l|l|}
\hline \multicolumn{1}{|c|}{ Assessment level } & \multicolumn{1}{c|}{ Description } \\
\hline Level I - Reaction & $\begin{array}{l}\text { The use of the questionnaire. Participants fill in the questionnaire after the end of each grade level and } \\
\text { all course of mentoring. Answers give the chance to obtain information allowing: } \\
\text { to collect and carry out the analysis of data on quality of mentoring; } \\
\text { to establish the reasons of satisfaction or dissatisfaction from mentoring among employees; } \\
\text { gives the chance of influence on mentoring and its improvement. }\end{array}$ \\
\hline Level II - Learning & $\begin{array}{l}\text { The use of tests. It is better to use the same test prior to training and after its end. It allows } \\
\text { demonstrating what the employee learned. This stage helps to define, not only concrete volume of } \\
\text { acquired skills and abilities by the employee, but also experience which will be used in practice. }\end{array}$ \\
\hline Level III - Behavior & $\begin{array}{l}\text { The feasibility of questionnaires' use, the procedure is similar to «360 degrees» method. The procedure } \\
\text { of observation of behavior change should be carried out prior to mentoring, then in two weeks after its } \\
\text { end and repeatedly in 2-3 months. }\end{array}$ \\
\hline Level IV - Results & $\begin{array}{l}\text { This assessment, gives the chance to reveal interrelation between mentoring and business processes and } \\
\text { their influence on interest of heads and employees in training, showing to heads what were the outputs } \\
\text { before and how they have grown up later. }\end{array}$ \\
\hline
\end{tabular}

Source: [7] [8]

The organizations of the private sector in the USA were the first type of the organizations which have introduced programs of mentoring for development of skills and competences of workers and their potential to exert positive impact on target groups. Soon after introduction of programs of mentoring in the private sector of the organization of public sector have begun to enter these programs. Some of early programs of mentoring of the USA have been directed not only to heads of an average link or higher senior positions, but also to trainees and new employees of the organization. Programs of this sort for heads, employees of an average and younger link and also specific target groups, such as women and indigenous people, have been realized in various public and educational institutions of Australia and New Zealand.

There is no universal model of mentoring available in the state or private sectors today. During discussion of mentoring in public service in New Zealand, Bhatta and Washington (2003) claim that mentoring can be presented from various points of view. First, mentoring it is possible to consider as type "intervention development" for the mentor and the ward. Secondly, from the organizational point of view mentoring is considered as process of "transfer" or socialization at which managers are socialized and introduced in norms and values of the organization which they support. These values are transmitted through mentoring process from one generation of heads to the following [8].
Mentoring can be both a short-term experience, and the long-term relations. In both cases there is a set of approaches for an effective interaction of the mentor and ward.

\section{REGIONAL SPECIFICS OF MENTORING REALIZATION IN HIGHER EDUCATION INSTITUTIONS}

The federal state-funded educational institution of the higher education "Grozny State Oil Technical University" is an oldest and first specialized oil higher education institution not only in our country, but also in the world.

It is necessary to reflect an essential mission of mentoring, the acceptable list of assistants (mentor), i.e. coincidence of his purposes and tasks, is reflected in the applied by the head ways to the choice of mentor. Choosing an assistant for the beginner, the head needs to adhere to some criteria. We consider priority of them: authority of the worker in a team:

- Great aspiration of the worker to education activity.

- Presence of a considerable working experience.

- Big practical experience, readiness of the worker to be a mentor.

- From the above it follows that for a further development of mentoring necessary is:

- To systematize material encouragement of workersmentors. 
- To recommend spiritual stimulation.

- To take away certain hours for training of the new employee.

- To grant to the mentor the right to perform work together with the beginner.

- The head needs to estimate work of the beginner systematically.

Today the mentor not only helps the beginner to join the staff, but also to improve own management skills. It is an additional responsibility since successful adaptation of the beginner is represented as demonstration of work quality of the mentor. The main objective of mentoring is an assistance to workers in occupation of a certain place, their professional development, both in a collective, and in Grozny State Oil Technical University named after M.D. Millionshikov.

The main tasks of mentoring in Grozny State Oil Technical University is a desire independently and qualitatively to explain in the course of training the main skills of a profession, learning of traditions and rules of conduct in this division and also adaptation to corporate culture. During the trial period, up to three months, mentoring over new workers is established. Generally big loading occurs in the first month, then the beginner addresses the mentor only if necessary, at emergence of problems, but not within the Plan of adaptation activities.

Mentors on Grozny State Oil Technical University are selected from the most trained employees who have high rates in work, have professionalism, dedicated, support standards and rules of work, have skills of communication and flexibility in communication, are ready to share experience, have a system idea of work area and work of division. Mentors of Grozny State Oil Technical University have to help new employees to enter gradually into collective and to find their own place in it.

Fixing of the employee as the mentor is carried out in the order on appointment of the employee by the trainee on positions, or appointment of him to a certain position. Presentation of the head of Grozny State Oil Technical University must be the basis for fixing of the mentor, important is the mutual consent of the alleged mentor and new employee to whom he will be assigned. The signs of assessment of work efficiency of the mentor are implementation of tasks and purposes by the new worker during the trial period and formation of good relationship in the group Grozny State Oil Technical University. Estimation of the new employee needs to be carried out as on intermediate, so on total control.

It is accepted to estimate mentoring at the end by method of 360 degrees, i.e. the worker is given an assessment from different levels: unit manager, mentor, colleagues, subordinates and from the certified himself. The material remuneration of the mentor will depend on this assessment.

Except material encouragement there is also a nonmaterial form of motivation of the mentor's work which has in the most part significant value for the employee and plays an important role for the mentor. Professional growth and recognition of the status in Grozny State Oil Technical University is a major part of non-material encouragement. Also, it gives the mentor a chance to show the skill and to promote on a career ladder [9]. During training of the beginner, the mentor makes plans of works, is engaged in the organization of working hours of the new employee and estimates his work. Such kind of activity gives the chance to the mentor Grozny State Oil Technical University not only to acquire skills of management, but also to gain experience of performance of organizational tasks. Cooperation with employees of human resources department and the head gives the mentor a chance to feel confident in the group Grozny State Oil Technical University. Formation of a positive image of the mentor as the most capable and responsible person, dear to both colleagues, and the management, is raised by natural desire of the beginner to appear on his place. Mentoring has to be not burdensome social work, but a form of rendering special trust.

The basic principles of mentoring guaranteeing success in this field in "Grozny State Oil Technical University" are [10]:

- The positive attitude towards a new employee;

- The rational distribution of working hours;

- The competent distribution of functions of mentoring;

- The continuity of mentoring of knowledge, experience transfer to the new employee;

- The control over learning during mentoring;

- The manifestation of care of the new employee: establishing a culture of the company;

\section{CONCLUSION}

Mentoring had a huge influence on formation of spirituality of the Russian nation that is especially accurately visible since adoption of Christianity in Russia and emergence of the main traditional religions in its territory. Today mentoring is the developed form of transfer to new employees of knowledge, experience and organizational culture [11]. It is a modern social institute which carries out the process of transfer of social experience, forms of continuity of generations in the organization, what has been lost today in modern Russia. Mentoring in a narrow concept, together with "coaching" and "tutoring", is an instrument of the adaptation process acceleration of the employee in a new workplace. Today it is clear to all of us that Russia needs purposeful unified state policy of moral revival of its people.

Mentoring in practice is recognized as technology of "investment into people", an effective way of personal growth and development of personnel of the organization. Mentoring can be both short-term experience, and the longterm relations. In both cases there is a set of approaches for effective interaction of the mentor and the ward. 


\section{REFERENCES}

[1] R. A. Shishov, Competences as criterion for evaluation of the candidate for mentors and activity of the mentor / R.A. Shishov // Management of development of personnel [Competences as criterion for evaluation of the candidate for mentoring and activity of the mentor / R.A. Shishov//Management of development of personnel], 2012, No. 2, pp. 164-172.

[2] A.A. Bagrakova, Mentoring in the organization /A.A. Bagrakova, Management of personnel development, 2008, No. 4, pp. 296-311.

[3] J. Oxley, Mentoring for Doctors: a look at the literature (work in progress) via Newcastle University Researchers mentoring programmer, 2004 - http://www.newcastle.ac.uk/

[4] Tammy D. Allen Career Benefits Associated with Mentoring for Protégés: A Meta-Analysis // Journal of Applied Psychology. 2004. Vol. 89. №. 1, pp. 127-136.

[5] A. Brockbank, I. McGill, Facilitating reflective learning through mentoring and coaching, Kogan Page Ltd USA, 2006.

[6] D. Lavin Colky \& W. Young, Mentoring in the virtual organization: Keys to building successful schools and businesses. Mentoring \& Tutoring, 14(4), 2006, pp. 433-447.

[7] Different Types of Business Mentoring Models [Electronic resource: URL: http://www.management-mentors.com

[8] Best Practices: Mentoring. United States Office of Personnel Management [Electronic resource]. - Sep. 2008. - URL: http://www.opm.gov/policy-data-oversight/training-anddevelopment/career-development/bestpracticesmentoring.pdf

[9] A.V. Frolova, A mentoring role in the course of passing the trial period / A.V. Frolova//Management today, 2008, No. 6, pp. 366-371.

[10] Yulia Romanova, Anna Egorenko, Scientific Methodological Approach to Effective Contract Assessment. Advances in Social Science, Education and Humanities Research. Proceedings of the 2017 International Conference on Culture, Education and Financial Development of Modern Society (ICCESE 2017) Copyright @ 2017 , the Authors. Published by Atlantis Press. This is an open access article under the CC BY-NC license Publication date May 2017 ISBN 978-94-6252-330-2 ISSN 2352-5398 doi:10.2991/iccese-17.2017.24 See for details: https://creativecommons.org/licenses/by$\mathrm{nc} / 4.0 / \mathrm{http}: / / \mathrm{www}$.atlantispress.com/php/pub.php?publication=iccese-17

[11] L. M. Cheglakova, Mentoring: new contours of the organization of social space of training and development of personnel of the industrial organizations/L. M. Cheglakova//Economic Sociology], 2011, vol. 12, No. 2, pp. 80-98. 